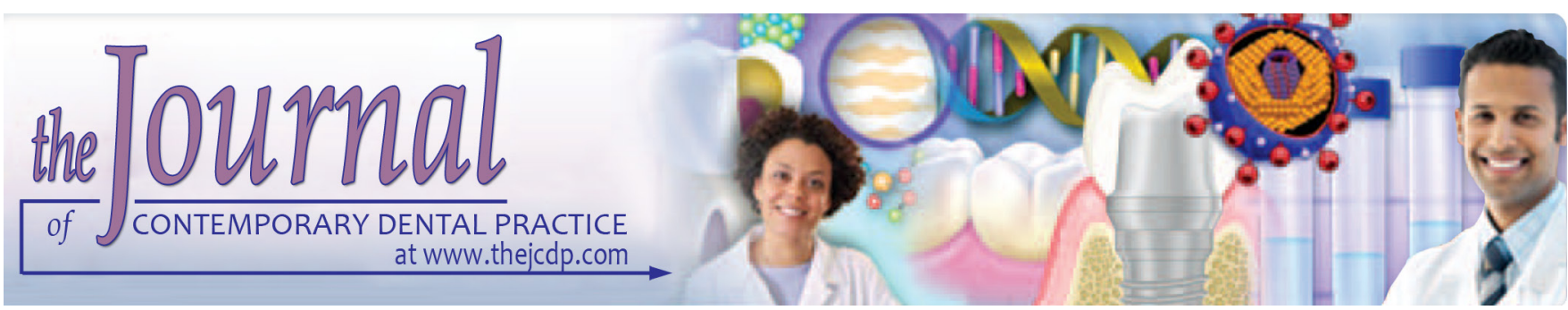

\title{
Clinical Evaluation of $10 \%$ Hydrogen Peroxide on Tooth Sensitivity and Effectiveness in at Home Dental Bleaching
}

\author{
${ }^{1}$ Kaprice Chemin, ${ }^{2}$ Márcia Rezende, ${ }^{3}$ Fábio M Milan, ${ }^{4}$ Thereza B Dantas, ${ }^{5}$ Kátia do N Gomes, ${ }^{6}$ Stella Kossatz
}

\begin{abstract}
Aim: The purpose of this study was to evaluate the dental effect and sensitivity of at-home dental bleaching with $10 \%$ hydrogen peroxide $\left(\mathrm{H}_{2} \mathrm{O}_{2}\right)$.

Materials and methods: Twenty volunteers with A2 or darker central incisors were selected for this study. Was used $10 \%$ $\mathrm{H}_{2} \mathrm{O}_{2}$ for thirty minutes twice a day, for two weeks. Shade evaluation was assessed visually by the value-oriented shade guide Vita Classical shade guide, Vita Bleachedguide 3D-MASTER and by the Easyshade spectrophotometer at baseline, during bleaching (first and second weeks), and post-bleaching (one month). The perceptions of sensitivity were recorded by the patients through the numerical rating scale ( 0 to 4$)$ and 0 to 10 visual analog scales daily. Data from the shade guide units was subjected to a one way repeated measures (RM) analysis of variance (ANOVA) test ( $\alpha=5 \%)$. The overall $\triangle \mathrm{E}$, absolute risk and intensity of tooth sensitivity were calculated as well as the $95 \%$ confidence interval.
\end{abstract}

Results: The absolute risk of tooth sensitivity was $65 \%$ and the intensity was mild. Data from $\triangle S G U$ and $\Delta E$ after 1 month of bleaching for $\mathrm{H}_{2} \mathrm{O}_{2} 10 \%$ showed significant whitening, 4 units for Vita Classical, 5 units for Vita Bleachedguide and 9.7 units for spectrophotometer.

Conclusion: At-home bleaching using $10 \%$ hydrogen peroxide is effective in 14 days of bleaching. The most common adverse events were mild tooth sensitivity, and no subjects discontinued use early because of a treatment-related adverse event.

Clinical significance: At-home dental bleaching with $10 \%$ hydrogen peroxide gel reduces the time of use of the tray, maintaining the effectiveness with low intensity of dental sensitivity. Brazilian clinical trials registry (REBEC) RBR-45xmzj.

Keywords: Dental bleaching, Dentin sensitivity, Hydrogen peroxide.

\footnotetext{
${ }^{1,6}$ Department of Restorative Dentistry, State University of Ponta Grossa, Paraná, Brazil

${ }^{2-5}$ School of Dentistry. Paulo Picanço School of Dentistry, Fortaleza, Ceará, Brazil

Corresponding Author: Márcia Rezende, School of Dentistry, Paulo Picanço School of Dentistry, Fortaleza, Ceará, Brazil, Phone: 85 3272-3222. e-mail: rezendemarcia@outlook.com
}

How to cite this article: Chemin K, Rezende M, Milan FM, Dantas TB, Gomes KDN, Kossatz S. Clinical Evaluation of $10 \%$ Hydrogen Peroxide on Tooth Sensitivity and Effectiveness in at-Home Dental Bleaching. J Contemp Dent Pract 2018; 19(11):1376-1380.

\section{Source of support: Nil}

\section{Conflict of interest: None}

\section{INTRODUCTION}

Tooth whitening is currently one of the most popular treatments in recent years as tooth color is considered of great importance to oral aesthetics. ${ }^{1,2}$

There are some teeth whitening techniques for vital teeth currently available for clinical use. Homemade whitening techniques have been used in dental practices for many years. At-home dental bleaching is a popular technique that has some advantages, such as its efficacy, low absolute risk of dentinal sensitivity, lower cost, and time required compared to in-office dental bleaching. ${ }^{3-6}$

Both techniques are usually performed with gels containing $\mathrm{H}_{2} \mathrm{O}_{2}$ and carbamide peroxide (CP) in different concentrations. The most commonly used at-home bleaching technique is $\mathrm{CP}$ at concentrations ranging from 10 to $22 \%$. Several studies have reported its efficacy and some adverse effects at different concentrations. ${ }^{6-11}$

When in contact with the tooth, $\mathrm{CP}$ dissociates into hydrogen peroxide and urea, which together with urea by-products may decrease the degradation of $\mathrm{CP} .{ }^{12}$ When in contact with dental structures, CP releases oxygen and peroxide in an anion hydrogen rupture and allows for the degradation of organic material, making it smaller and lighter. As $\mathrm{H}_{2} \mathrm{O}_{2}$ is known to penetrate the dental tissue faster than CP because of its low molecular weight ${ }^{13,14}$, it also has a shorter action time than $\mathrm{CP}$, which needs to dissociate into $\mathrm{H}_{2} \mathrm{O}_{2}$ and urea. Hydrogen peroxide, when in contact with the tooth, immediately begins 
the whitening process by releasing oxygen. Thus, when used in low concentrations, $\mathrm{H}_{2} \mathrm{O}_{2}$ is a good alternative technique that requires less time to use than the tray. ${ }^{15}$

Little is said about $\mathrm{H}_{2} \mathrm{O}_{2}$ in low concentrations regarding at-home dental bleaching's effectiveness and adverse effects. This study aimed to evaluate the effectiveness of color, stability of color, and dental sensitivity in the use of $10 \% \mathrm{H}_{2} \mathrm{O}_{2}$ (White Class, FGM Dental Products, Joinville, Brazil) in at-home bleaching.

\section{MATERIALS AND METHODS}

This clinical investigation was approved (protocol number 1.009.881) by the Scientific Review Committee and by the committee for the protection of human subjects of the local university. This report follows the protocol established by the Consolidated Standards of Reporting Trials (CONSORT) statement. ${ }^{16}$ Based on pre-established criteria, 20 volunteers who searched for dental bleaching were selected for this study. The study was performed between March 2015 and June 2015. All of the volunteers received dental prophylaxis with pumice and water in a rubber cup two weeks before the bleaching procedures and signed an informed consent form.

\section{Eligibility Criteria}

The participants who were included in this clinical trial had good general and oral health and were at least 18 years of age. The participants were required to have no periodontal disease and at least six caries-free maxillary anterior teeth. The central incisors were shade $\mathrm{A} 2$ or darker, in comparison with a value-oriented shade guide (Vita Classical, Vita Zahnfabrik, Bad Säckingen, Germany).

Participants with a dental prosthesis, orthodontic apparatus, anterior restorations, or severe internal tooth discoloration (fluorosis, tetracycline stains, pulpless teeth) were not included in the study. Pregnant/lactating women, participants with any other pathology that could cause sensitivity (such as dentine exposure, the presence of visible cracks in teeth or recession), bruxists, or participants who had previously undergone dental bleaching procedures were also excluded.

\section{Bleaching Procedure}

Participants were molded in the upper and lower arches with avagel alginate (Dentsply, Petrópolis, RJ, Brazil); they were disinfected and immediately after filled with dental stone (Asfer, Asfer Indústria Química Ltda., São Caetano do Sul, SP, Brazil). No block-out material was applied to the labial surfaces of teeth to produce study models. ${ }^{8}$ The plaster models were cut out to make the individual $0.9-\mathrm{mm}$ thick ethylene-vinyl acetate trays (Whiteness Molding Plates-FGM, Joinville, Santa
Catarina, Brazil), provided by the manufacturer in vacuum plasticizer (Plastivac P7, BioArt, São Carlos, Brazil), to produce the custom-fitted tray that would retain the whitening gel.

The trays were tested to make sure they were fully adapted in the dental arches of participants and the extra material from the labial and lingual surfaces was trimmed to $1 \mathrm{~mm}$ from the gingival junction. The bleaching tray and $10 \% \mathrm{H}_{2} \mathrm{O}_{2}$ gel (White Class, FGM Dental Products, Joinville, Brazil) were delivered to each participant, with oral clear and detailed instruction for use. All participants should use the tray with the bleaching agent for thirty minutes twice a day for 2 weeks. After 30 minutes of bleaching, the participant was instructed to remove the tray and perform a vigorous mouthwash with water, so that the whitening gel was removed entirely, and brush their teeth as usual. After 12 hours the procedure was repeated. In concern to oral hygiene, all participants were instructed to brush their teeth regularly and use toothpaste without bleaching agents and desensitizers for daily brushing. ${ }^{17}$

\section{Shade Evaluation}

Shade evaluation was performed with the use of subjective and objective evaluation methods. For the subjective assessment, the 16 tabs of the shade guide (Vita Classic, Vita Zahnfabrik) ${ }^{18,19}$ were organized from highest (B1) to the lowest (C4) value. Despite this scale is not linear in the truest sense, for the purpose of analysis, the changes were treated as though they represented a continuous and approximately linear ranking. The Vita Bleachedguide 3D-MASTER (Vita Zahnfabrik) ${ }^{11,20,21}$ contains lighter shade tabs and is already arranged from highest (0M1) to lowest (5M3) value. The area of color measurement was determined in the middle third of the vestibular face of the upper central incisor according to the specifications of the American Dental Association (ADA) guidelines.

Two calibrated evaluators (K.C. and M.R.) with an agreement of at least $85 \%$ as determined by weighted kappa statistics recorded the shade of each subject's teeth at baseline, during treatment (after the first and second weeks of go through bleaching treatment), and 1 month after completion of tooth whitening. Shade changes were calculated from the beginning of the active phase through the individual recall times by calculating the change in the number of shade guide units ( $\triangle \mathrm{SGU}$ ), which occurred toward the lighter end of the value-oriented list of shade tabs. In the event of disagreements between the examiners during shade evaluation, a consensus was reached.

For objective evaluation, the digital Vita Easyshade spectrophotometer (Vita Easyshade, Vita Zahnfabrik) ${ }^{18,19}$ was used right after the subjective shade evaluation. 
To standardize the color measurement, the upper arch of the patients' arches was molded with dense silicone paste (Speedex Putty, Coltene, Rio de Janeiro, Brazil) to make a matrix on the upper anterior teeth. The impression was extended to the maxillary canine and the matrix was punctured with the aid of a $6 \mathrm{~mm}$ diameter circular scalpel, Biopsy Punch (Miltex, York, Pennsylvania, USA) in the region corresponding to each dental component to be evaluated in the vestibular face, the middle third of the right upper central incisor tooth. ${ }^{21,22}$

The shade was determined using the parameters of the Easyshade device on which the following values were indicated: $L^{*}, a^{*}$, and $b^{*}$, where $L^{*}$ represents the value from 0 (black) to 100 (white) and $a^{*}$ and $b^{*}$ represent the shade, where $a^{*}$ is the measurement along the red-green axis and $b^{*}$ is the measurement along the yellow-blue axis. The color comparison before and after treatment is given by the differences between the two colors $(\Delta \mathrm{E})$, which is calculated using the formula $\Delta \mathrm{E}=\left[\left(\Delta \mathrm{L}^{*}\right)^{2}+\left(\Delta \mathrm{a}^{*}\right)^{2}+\right.$ $\left.\left(b^{*}\right) 2\right]^{1 / 2}$ (Commission Internationale de l'Eclairage 1978). ${ }^{23}$

\section{Tooth Sensitivity Evaluation}

The patients recorded the occurrence or nonoccurrence of dental sensitivity using the five-point analogue numerical scale (NRS), $0=$ none, $1=$ mild, $2=$ moderate, $3=$ considerable and $4=$ severe $^{8,21,22}$ and visual analogue scale (VAS), with extreme 0 representing no pain and extreme 10 representing severe pain. Then, the distance in $\mathrm{mm}$ from the zero was measured with the aid of a millimeter ruler. ${ }^{21-24}$ The tooth sensitivity was recorded every day, in both scales.

\section{Statistical Analysis}

The color change comparisons between times from Vita Classical scale, Vita Bleachedguide, and $\Delta \mathrm{E}$ were performed using one-way repeated measures analysis of variance.

\section{RESULTS}

\section{Characteristics of Included Participants}

A total of 69 participants were screened to select 20 participants who met the inclusion criteria (Fig. 1).
The mean age of the participants was $25.7 \pm 7.5$ years, with a range of 18 to 51 years; $50 \%$ of the participants were women. All of the participants attended the recall visits during the bleaching protocol (Fig. 1). The adherence to protocol was $90 \%$, meaning that patients did not use the bleaching tray sometimes during the two-week period.

\section{Tooth Sensitivity}

The absolute risk of tooth sensitivity of the participants was $65 \%$ (95\% CI 46 to $93 \%$ ), with a mean VAS intensity of $2.0 \pm 2.3(95 \%$ CI 0.9 to 3.0$)$ and NRS of $1.2 \pm 1.2(95 \%$ CI 0.6 to 1.7$)$.

\section{Color Evaluation}

Significant whitening was observed after bleaching under the subjective and objective evaluation methods. A change in the shade guide units within the Vita Classical was $4.0 \pm 0.9$ and Bleached guide $5.0 \pm 1.4$. In terms of $\Delta \mathrm{E}$, the change in color was $9.7 \pm 5.3$. Most of the whitening occurred within the first week of bleaching as can be observed by the three different instruments used for evaluation of color changes, and the color remained stable when assessed 1-month postbleaching (Table 1).

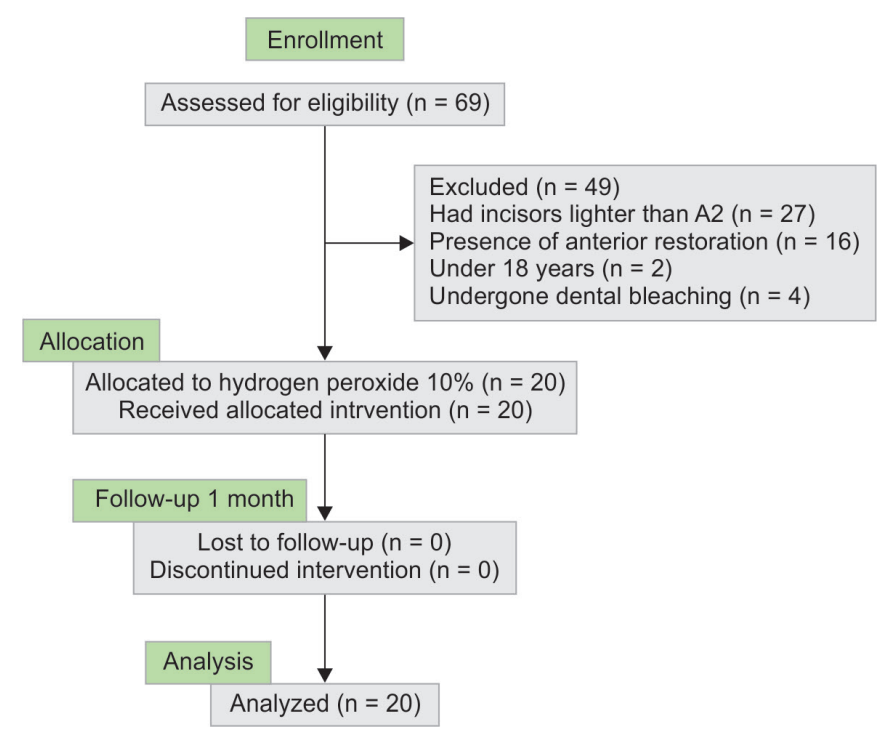

Fig. 1: Flow diagram of the clinical trial, including enrollment and allocation criteria

Table 1: Means and standard deviations of $\Delta S G U$ and $\Delta E$ values obtained in subjective and objective evaluation in different periods

\begin{tabular}{llll}
\hline & \multicolumn{2}{c}{$\Delta S G U$} & $\Delta E$ \\
\cline { 2 - 4 } Evaluation period & Vita Classical & Vita Bleachedguide & $8.3 \pm 3.8 \mathrm{a}$ \\
\hline Baseline vs. 1 week & $3.0 \pm 1.0 \mathrm{a}$ & $3.0 \pm 2.4 \mathrm{a}$ & $9.9 \pm 3.6 \mathrm{a}$ \\
Baseline vs. 2 week & $4.0 \pm 0.9 \mathrm{~b}$ & $5.0 \pm 2.2 \mathrm{~b}$ & $9.7 \pm 5.3 \mathrm{a}$ \\
Baseline vs. 1 month follow-up & $4.0 \pm 0.9 \mathrm{~b}$ & $5.0 \pm 1.4 \mathrm{~b}$ & 0.10 \\
p-value & $<0.001$ & $<0.001$ & \\
\hline
\end{tabular}




\section{DISCUSSION}

The protocol of at-home dental bleaching used in this study was effective. After two weeks of bleaching, a clinically visible color change of the teeth was verified. Most of the sample reached B1/A1 color according to the Vita Classical scale at the end of treatment. The findings of this study corroborate those of a similar study of da Costa et al. ${ }^{20}$ that used a concentration close or equal to $\mathrm{H}_{2} \mathrm{O}_{2} 10 \%$ and produced a bleaching of ${ }^{3}$ units according to the Vita Bleachedguide. In this study, it produced a bleaching of 4 units with Vita Classical and 5 units of color change with Vita Bleachedguide. Color remained stable after 1 month of bleaching treatment.

At-home bleaching is practical in that it allows for a protocol more flexible and adaptable to routine, and some patients have demonstrated a preference for this technique. ${ }^{20,25}$ The $10 \%$ carbamide peroxide has been the peroxide of choice for at-home bleaching, considered the gold standard by the ADA. However, the use of $\mathrm{H}_{2} \mathrm{O}_{2}$ for at-home bleaching may be advantageous since the protocol requires a shorter use time of the tray, ${ }^{25,26}$ by an action mechanism other than carbamide peroxide. ${ }^{18,19,26-29}$ The protocol of this study proved to be effective even with the reduction of time because the degree of dental bleaching depends on hydrogen peroxide concentration, frequency, and time period that the bleaching agent is in contact with macromolecules. ${ }^{30}$ Also, 10\% hydrogen peroxide is the highest concentrated at-home bleaching agent, and as a result can require less time in contact with the dental element to produce satisfactory whitening.

The absolute risk of dental sensitivity induced by whitening indicated that $65 \%$ of the volunteers reported sensitivity at some point during the protocol, which is corroborated by the study by Bizhang et al., ${ }^{31}$ who reported an absolute risk of $60 \%$ to $72 \%$. This augment occurs because hydrogen peroxide penetrates through enamel and dentin, expanding the dental permeability reaching the pulp and causing the release of inflammatory mediators in the dental pulp, ${ }^{32}$ which may cause tooth sensitivity after bleaching.

Although most of the volunteers reported dental sensitivity, the level of sensitivity was mild. This may be related to the fact that the $\mathrm{H}_{2} \mathrm{O}_{2}$ used in this study has in its composition potassium nitrate and sodium fluoride as desensitizing agents. It also contains calcium in its formula, which has the purpose of minimizing the enamel demineralization process. In other words, the incorporation of desensitizers into the gel, with different mechanisms, while not reducing the risk, reduces the sensitivity intensity. De la Peña and Cabrita ${ }^{33}$ carried out a study in which participants reported lower incidence of dental sensitivity after at-home bleaching with bleaching gels that contained desensitizing agents. The study of Parreiras et al. ${ }^{32}$ also reported that the use of $5 \%$ potassium nitrate and $2 \%$ sodium fluoride halved the concentration of hydrogen peroxide in the pulp chamber, and this reduction can be explained by the increased resistance of dental enamel caused by the presence of sodium fluoride or by its presence within the dental structure.

Despite the findings of this study, more research should be conducted to compare different effects, techniques, application times, and bleaching agents.

\section{CONCLUSION}

The use of $10 \%$ hydrogen peroxide for at-home bleaching techniques is effective when used thirty minutes twice a day for two weeks and presents low sensitivity with reduced time of use of the tray.

\section{CLINICAL RELEVANCE}

At-home dental bleaching with 10\% hydrogen peroxide gel reduces the time of use of the tray, maintaining the effectiveness with low intensity of dental sensitivity.

\section{ACKNOWLEDGMENT}

The authors would like to thank FGM Dental Products for the donation of the bleaching gel used in this investigation. The authors also declare that they have no conflict of interest.

\section{REFERENCES}

1. Kihn PW. Vital Tooth Whitening. Dent Clin N Am 2007 Apr; 51(2):319-331.

2. Matis BA, Wang G, Matis JI, Cook NB, Eckert GJ. White diet: is it necessary during tooth whitening? Oper Dent 2015 MayJun; 40(3):235-240.

3. Perdigão J, Baratieri LN, Arcari GM. Contemporary trends and techniques in tooth whitening: a review. Pract Proced Aesthet Dent 2004 Apr; 16(3):185-192

4. Browning, WD, Blalock, JS, Frazier, KB, Downey, MC, Myers, ML. Duration and timing of sensitivity related to bleaching. J Esthet Restor Dent 2007 Oct; 19(5):256-264.

5. Meireles SS, Heckmann SS, Leida FL, dos Santos Ida S, Della Bona A, Demarco FF. Efficacy and safety of $10 \%$ and $16 \%$ carbamide peroxide tooth-whitening gels: a randomized clinical trial. Oper Dent 2008 Nov-Dec; 33(6):606-612.

6. Basting RT, Amaral FLB, França FMG, Flório FM. Clinical comparative study of the effectiveness of and tooth sensitivity to $10 \%$ and $20 \%$ carbamide peroxide home-use and $35 \%$ and $38 \%$ hydrogen peroxide in-office bleaching materials containing desensitizing agents. Oper Dent 2012 Sep-Oct; 37(5):464-473.

7. Demarco FF, Meireles SS, Sarmento HR, Dantas RVF, Botero T, Tarquinio SBC. Erosion and abrasion on dental structures undergoing at-home bleaching. Clin Cosmet Investig Dent 2011 Jul; 18(3):45-52. 
8. Rezende M, Loguercio AD, Reis A, Kossatz S. Clinical effects of exposure to coffee during at-home vital bleaching. Oper Dent 2013 Nov-Dec; 38(6):E229-E236.

9. Hyland BW, McDonald A, Lewis N, Tredwin C, Petrie A, Hall S, Callan JF. A new three-component formulation for the efficient whitening of teeth (Carbamide Plus). Clin Oral Investig 2015 Jul; 19(6):1395-1404.

10. Almeida LC, Soares DG, Azevedo FA, Gallinari MD, Costa CA, Santos PH, Briso AL At-Home Bleaching: Color Alteration, Hydrogen Peroxide Diffusion and Cytotoxicity. Braz Dent J 2015 Jul-Aug; 26(4):378-383.

11. De Geus JL, Bersezio C, Urrutia J, Yamada T, Fernández E, Loguercio AD, Reis A, Kossatz S. Effectiveness of and tooth sensitivity with at-home bleaching in smokers: A multicenter clinical trial. J Am Dent Assoc 2015 Apr; 146(4):233-240.

12. Al-Qunaian TA, Matis BA, Cochran MA. In vivo kinetics of bleaching gel with three-percent hydrogen peroxide within the first hour. Oper Dent 2003 May-Jun; 28(3):236-241.

13. Hanks CT, Fat JC, Wataha JC, Corcoran JF. Cytotoxicity and dentin permeability of carbamide peroxide and hydrogen peroxide vital bleaching materials, in vitro. J Dent Res 1993 May; 72(5):931-938.

14. Oliver TL, Haywood VB. Efficacy of nightguard vital bleaching technique beyond the borders of a shortened tray. J Esthet Dent 1999; 11(2):95-102.

15. Myers ML, Browning WD, Downey MC, Hackman ST. Clinical Evaluation of a 3\% Hydrogen Peroxide Tooth Whitening Gel. J Esthet Restor Dent 2003 Jan; 15(1), 50-55.

16 Schulz KF, Altman DG, Moher D, CONSORT Group. CONSORT 2010 Statement: Updated guidelines for reporting parallel group randomised trials. Int J Surg. 2011 Oct; 9(8):672-677.

17. Papas AS, Kugel G, Singh M, Barker ML, Gerlach RW. Placebo-controlled clinical trial of use of $10 \%$ hydrogen peroxide whitening strips for medication-induced xerostomia. Gerontology. 2009 Aug; 55(5):511-516.

18. Alonso de la Peña V, López Ratón M. Randomized clinical trial on the efficacy and safety of four professional at-home tooth whitening gels. Oper Dent 2014 Mar-Apr; 39(2):136-143.

19. Martín J, Vildósola P, Bersezio C, Herrera A, Bortolatto J, Saad JRC, Fernández E. Effectiveness of $6 \%$ hydrogen peroxide concentration for tooth bleaching - A double-blind, randomized clinical trial. J Dent 2015 Aug; 43(8):965-972.

20. Da Costa JB, McPharlin R, Hilton T, Ferracane JL, Wang M. Comparison of two at-home whitening products of similar peroxide concentration and different delivery methods. Oper Dent 2012 Jul-Aug; 37(4):333-339.
21. Rezende M, Bonafe E, Vochikovski L, Farago PV, Loguercio $\mathrm{AD}$, Reis A, Kossatz S. Pre- and postoperative dexamethasone does not reduce bleaching-induced tooth sensitivity: A randomized, triple-masked clinical trial. J Am Dent Assoc 2016 Jan;147(1):41-49.

22. Bernardon JK, Sartori N, Ballarin A, Perdigão J, Lopes GC, Baratieri LN. Clinical performance of vital bleaching techniques. Oper Dent 2010 Jan-Feb; 35(1):3-10.

23. De l'Eclairage CI. Recommendations on uniform color spaces, color-difference equations, psychometric color terms. Paris: CIE. 1978.

24. Dawson PF, Sharif MO, Smith AB, Brunton PA. A clinical study comparing the efficacy and sensitivity of home vs combined whitening. Oper Dent 2011 Sep-Oct; 36(5):460-466.

25. Ghalili KM, Khawaled K, Rozen D, Afsahi V. Clinical study of the safety and effectiveness of a novel over-the-counter bleaching tray system. Clin Cosmet Investig Dent 2014 Feb; 21(6):15-19.

26. Delgado E, Hernández-Cott PL, Stewart B, Collins M, De Vizio W. Tooth-whitening efficacy of custom tray-delivered $9 \%$ hydrogen peroxide and $20 \%$ carbamide peroxide during daytime use: a 14-day clinical trial. P R Health Sci J. 2007 Dec; 26(4):367-372.

27. Silva FM, Nacano LG, Pizi ECG. Clinical evaluation of two dental bleaching systems. ROBRAC 2012; 21(57):473-479.

28. Zhao K, Zong L, Zhang Q, Att W. Clinical comparison between two bleaching techniques: a 180-day follow-up study. Quintessence Int 2013 Jul; 44(8):601-607.

29. Sundfeld RH, Neto DS, Machado LS, de Oliveira FG, de Alexandre RS, Palo RM, Sundefeld MM. Dental bleaching with a $10 \%$ hydrogen peroxide product: A six-month clinical observation. Indian J Dent Res 2014 Jan-Feb; 25(1):4-8

30. Cardoso PC, Reis A, Loguercio A, Vieira LC, Baratieri LN. Clinical effectiveness and tooth sensitivity associated with different bleaching times for a 10 percent carbamide peroxide gel. J Am Dent Assoc 2010 Oct; 141(10):1213-1220.

31. Bizhang M, Chun YP, Damerau K, Singh P, Raab WH, Zimmer S. Comparative clinical study of the effectiveness of three different bleaching methods. Oper Dent 2009 Nov; 34(6):635-641.

32. Parreiras SO, Vianna P, Kossatz S, Loguercio AD, Reis A. Effects of light activated in-office bleaching on permeability, microhardness, and mineral content of enamel. Oper Dent 2014 Sep/Oct; 39(5):E225-E223.

33. De la Pena VA, Cabrita OB. Comparison of the clinical efficacy and safety of carbamide peroxide and hydrogen peroxide in at-home bleaching gels. Quintessence Int 2006 Jul/Aug; 37(7):551-556. 